\title{
Does gender influence morbidity or mortality in the surgical treatment of renal masses?
}

\author{
Brian J. Minnillo, MD; ${ }^{*}$ Andrew Horowitz, MD; ${ }^{*}$ Antonio Finelli, MD, MSc, FRCSC; ${ }^{\dagger}$ Shabbir M.H. Alibhai, MD, \\ MSc, FRCSC;, Lee E. Ponsky, MD; Robert Abouassaly, MD, MSc, FRCSC ${ }^{*}$
}

*Urological Institute, University Hospitals Case Medical Center, Case Western Reserve University, Cleveland, OH; †Department of Surgical Oncology, Princess Margaret Hospital, University of Toronto, Toronto, ON; §Department of Medicine, University of Toronto, Toronto, ON

Cite as: Can Urol Assoc J 2014;8(5-6):e311-6. http://dx.doi.org/10.5489/cuaj.1674 Published online May 21, 2014.

\section{Abstract}

Introduction: We determine the relationship between gender and surgical morbidity after radical nephrectomy (RN) and partial nephrectomy (PN) for renal masses on a population level.

Methods: We conducted a population-based, retrospective study using the Canadian Institute for Health Information Discharge Abstract Database. This included 20286 RNs (82.5\%) and 4292 PNs (17.5\%) from April 1, 1998 to March 31, 2008. Complications were identified by ICD-9 and 10 codes, and comorbidity was assessed with the Charlson Index. The association between gender and in-hospital complication rates and mortality were examined using the Chi-square test, as well as with multivariable logistic regression, adjusting for explanatory variables including type of surgery, age, and comorbidity.

Results: Overall, men experienced a higher unadjusted complication rate than women $(35.1 \%$ vs. $32.7 \%)$, as well as a higher unadjusted in-hospital mortality rate $(1.46 \%$ vs. $0.84 \%)$, respectively. Men also demonstrated significantly higher rates of cardiac, wound, nephrectomy-specific, and medical complications. Women experienced fewer complications than men after RN $(p=0.0002)$, but not after PN ( $p=0.33)$. On multivariable logistic regression analysis, women had a lower overall complication rate (odds ratio [OR] 0.94, 95\% confidence interval [CI] 0.88-0.99), and a lower inhospital mortality rate (OR $0.64,95 \% \mathrm{Cl} 0.49-0.83)$ after kidney surgery.

Conclusions: In our population-based analysis, in-hospital morbidity after renal surgery was significantly lower for women. Further study is needed to determine if the observed effect is related to differences in surgical difficulty, perioperative care, or unmeasured confounders.

\section{Introduction}

Studies investigating gender-related morbidity and mortality of renal surgery for renal cell carcinoma (RCC) are not commonly seen in the urologic literature. New healthcare programs are striving to decrease treatment-related disparities, as well as to monitor use and access to care. There has been an increase in the detection of small renal masses due to the increased use of abdominal imaging. Radical nephrectomy ( $\mathrm{RN}$ ) and partial nephrectomy (PN) are the standard of care for a renal mass which is suspected to be malignant. ${ }^{1-3}$ An understanding of the gender-related morbidity of distinct treatment interventions can be important in counselling patients and offering prognostic information..$^{2-5}$ Large epidemiological studies using databases in Europe and the United States, including the Pathological Anatomical National Automated Archive (PALGA) and National Cancer Database, respectively, have investigated gender differences in the presentation of RCC. ${ }^{4,5}$

Current published data of surgical morbidity tend to originate from academic tertiary referral centers ${ }^{6,7}$ which may not accurately reflect the morbidity of renal surgery in community practices. Although increased age has already been shown to be associated with increased morbidity and mortality after renal surgery, ${ }^{8}$ the impact of other patient characteristics on postoperative complications are not clearly defined. Women tend to present with smaller tumours, lower grade, and lower stage disease. Also, women may have less severe comorbidities (i.e., hypertension, diabetes, chronic obstructive pulmonary disease, congestive heart failure) that may allow them to experience better recovery after surgery. ${ }^{8}$

Reporting surgical complication data is important in that it allows physicians to more accurately counsel their patients prior to intervention. Our objective was to determine the effect of gender on patient morbidity and in-hospital mortality after RN and PN.

\section{Methods}

\section{Patient selection}

We performed a population-based, retrospective, observational study using the Canadian Institute for Health 
Information (CIHI) Discharge Abstract Database (DAD), which provides information from 9 out of 10 Canadian provinces. ${ }^{9}$ Data for this study included all hospitalized patient records treated by either $\mathrm{RN}$ or $\mathrm{PN}$. These records were identified using either specific Canadian Classification of Diagnostic, Therapeutic, and Surgical Procedures (CCP) codes which correspond to the 9th revision of the International Classification of Disease (ICD-9), or Canadian Classification of Health Interventions $(\mathrm{CCl})$ procedure codes, which correspond to the ICD-10.

The study included discharge abstracts on all patients treated by either $\mathrm{RN}$ or $\mathrm{PN}$ at acute inpatient facilities from April 1, 1998 to March 31, 2008. ${ }^{9}$ We excluded patients under 18 years old and patients who underwent nephrectomy for anything other than a solid or cystic renal mass (e.g., urothelial carcinoma, infection, polycystic kidney disease, non-functional kidney). This dataset is a re-analysis of a previously published dataset assessing the morbidity of kidney surgery. ${ }^{8}$ Research Ethics Board approval was obtained from the University of Toronto.

\section{Comorbidities}

We used the Deyo adaptation of the Charlson Index as a measure of comorbidity. This method has been validated for use with administrative data using ICD-9 and ICD-10 diagnosis codes..$^{10,11}$

\section{Complications}

In-hospital complications were identified using ICD-9 and ICD-10 diagnostic and procedure codes that have been described in other published studies of renal cell carcinoma. ${ }^{6,7}$ Complications were grouped into major organ systems: cardiac, pulmonary, vascular, wound/bleeding, genitourinary, nephrectomy-specific, miscellaneous surgical, and miscellaneous medical. Nephrectomy-specific complications included control kidney bleeding, drainage of kidney, need for dialysis, repair of ureter, ureteral stenting, and $\mathrm{RN}$ after index PN. ${ }^{8}$

\section{Statistical analyses}

Descriptive information on pertinent variables was generated for all patients, as well as stratified by treatment type (RN vs. PN). Mean, ranges, and standard deviations were reported for continuous variables and proportions were reported for categorical variables. The mean of continuous variables were compared using the t-test, whereas categorical variables were compared using the chi-square test, univariate and multivariable logistic regressions. Since the model was meant to determine associations rather than being used as a prediction tool, a reductionist model-building strategy was not used to determine variable inclusion; rather, all predetermined variables were included in the model (i.e., gender, year of surgery, patient age, geographical region, surgeon and hospital volume, Charlson score, procedure type [RN or $\mathrm{PN}]$, and patient income). Odds ratio (OR) estimates and $95 \%$ confidence intervals $(\mathrm{Cl})$ were obtained for all strata. Logistic model calibration and discrimination were assessed with the Hosmer-Lemeshow and c-statistic, respectively. Statistical significance was defined as a $p$ value less than 0.05. All analyses were performed using SAS v.9.2 (SAS Institute Inc, Cary, NC).

\section{Results}

A total of 24578 kidney surgeries were included in our study: 20286 (82.5\%) RN and 4292 (17.5\%) PN from April 1, 1998 to March 31, 2008 (Table 1). Overall, more men were treated than women: 14769 (60.1\%) vs. 9810 (39.9\%), respectively. In our population, men had significantly higher comorbidity than women, with a greater proportion of men with Charlson scores of $2(7.6 \%$ vs. $5.7 \%)$ and $\geq 3(3.6 \%$ vs. $2.2 \%)$ compared with women $(p<0.0001)$ (Table 1). The specific comorbidities which were greater for men and statistically significant included myocardial infarction, peripheral vascular disease, peptic ulcer disease, complications of diabetes mellitus, renal insufficiency, all cancers (excluding kidney cancer), severe liver disease, and human immunodeficiency virus. However, the proportion of dementia patients was similar $(p=0.0748)$ and connective tissue disorder $(p<0.0001)$ was the only comorbidity that was greater for women (Table 1).

The unadjusted overall complication rate for all kidney surgery was higher in men compared with women, $35.1 \%$ vs. $32.7 \%$ ( $p<0.0001)$. Even after adjusting for potential confounders on multivariable logistic regression analysis, women had a lower overall complication rate (OR 0.94, $95 \% \mathrm{Cl}$ 0.88-0.99). When complications were stratified by major organ system, our results demonstrated that men had a higher rate of cardiac, wound, nephrectomy-specific, and medical miscellaneous complications; however male gender was associated with lower genitourinary and miscellaneous surgical complication rates.

There was no significant difference $(p=0.37)$ in the proportion of RNs ( $82.7 \%$ vs. $82.3 \%$ ) or PNs (17.3\% vs. $17.7 \%)$ performed in men versus women, respectively (Table 1 ). Women experienced fewer complications after RN compared to men ( $p=0.0002)$, but there was no difference after PN $(p=0.33)$. Even after adjusting for covariates, women had fewer complications after RN (OR 0.92, 95\% Cl 0.87$0.98, p=0.011$ ); however, gender had no effect on complications after PN (OR 0.99, 95\% Cl 0.87-1.14, $p=0.93$ ) (Table 2).

Although complications increased with age for both men and women, the absolute difference between patients aged 


\begin{tabular}{|c|c|c|c|c|}
\hline Variable & Total (\%) & Male (\%) & Female (\%) & $p$ value \\
\hline Nephrectomy type & & & & 0.3733 \\
\hline Total & 24579 & $14769(60.1)$ & 9810 (39.9) & \\
\hline Radical nephrectomy & 20286 (82.5) & $12215(82.7)$ & $8071(82.3)$ & \\
\hline Partial nephrectomy & 4292 (17.5) & $2553(17.3)$ & $1739(17.7)$ & \\
\hline Age & & & & 0.0001 \\
\hline$<50$ years & $4613(18.8)$ & $2636(17.9)$ & $1977(20.1)$ & \\
\hline $50-59$ years & $5885(23.9)$ & $3613(24.5)$ & $2272(23.2)$ & \\
\hline $60-69$ years & $6609(26.9)$ & $4179(28.3)$ & $2430(24.8)$ & \\
\hline $70-79$ years & $5852(23.8)$ & $3463(23.4)$ & $2389(24.3)$ & \\
\hline$>80$ years & $1620(6.6)$ & $878(5.9)$ & $742(7.6)$ & \\
\hline Mean age (standard deviation) & $61.4(13.0)$ & $61.49(12.5)$ & $61.34(13.6)$ & 0.3879 \\
\hline Charlson score & & & & $<0.0001$ \\
\hline 0 & $18521(75.4)$ & $10871(73.6)$ & $7650(78.0)$ & \\
\hline 1 & $3635(14.8)$ & $2255(15.3)$ & $1380(14.1)$ & \\
\hline 2 & $1681(6.8)$ & $1118(7.6)$ & $563(5.7)$ & \\
\hline$\geq 3$ & $742(3.0)$ & $525(3.5)$ & $217(2.2)$ & \\
\hline \multicolumn{5}{|l|}{ Comorbidities } \\
\hline Myocardial infarction & $717(2.92)$ & $537(3.64)$ & $180(1.83)$ & $<0.0001$ \\
\hline Congestive heart failure & $529(2.15)$ & $322(2.18)$ & $207(2.11)$ & 0.7642 \\
\hline Peripheral vascular disease & $300(1.22)$ & $233(1.58)$ & $167(0.68)$ & $<0.0001$ \\
\hline Cerebrovascular disease & $207(0.84)$ & $128(0.88)$ & $79(0.80)$ & 0.1842 \\
\hline Dementia & $38(0.15)$ & $16(0.11)$ & $22(0.22)$ & 0.0748 \\
\hline Pulmonary disease & $1265(5.15)$ & $776(5.25)$ & 489 (4.98) & 0.3526 \\
\hline Connective Tissue disorder & $111(0.45)$ & $44(0.3)$ & $67(0.68)$ & $<0.0001$ \\
\hline Peptic ulcer disease & $87(0.35)$ & $69(0.47)$ & $18(0.18)$ & 0.0012 \\
\hline Liver disease & $46(0.19)$ & $31(0.21)$ & $15(0.15)$ & 0.4775 \\
\hline Diabetes mellitus & $2377(9.67)$ & $1464(9.91)$ & $903(9.20)$ & 0.1630 \\
\hline Complications of diabetes mellitus & $286(1.16)$ & $196(1.33)$ & $90(0.92)$ & 0.0222 \\
\hline Paraplegia & $47(0.19)$ & $31(0.21)$ & $16(0.16)$ & 0.5570 \\
\hline Renal insufficiency & $807(3.28)$ & $570(3.86)$ & $237(2.41)$ & $<0.0001$ \\
\hline All localized cancer (excluding kidney) & $849(3.45)$ & $572(3.87)$ & $277(2.83)$ & $<0.0001$ \\
\hline All metastatic cancer (excluding kidney) & $31(0.13)$ & $21(0.14)$ & $10(0.10)$ & 0.4304 \\
\hline Severe liver disease & $1816(7.69)$ & 1194 (8.09) & $622(6.35)$ & $<0.0001$ \\
\hline Human immunodeficiency virus & $9(0.0003)$ & $9(0.06)$ & $0(0.0)$ & 0.0145 \\
\hline
\end{tabular}

$<50$ and those $\geq 80$ was greater for men than for women $(18.5 \%$ vs $14.4 \%, p<0.0001)$ (Fig. 1a). When compared by gender, the difference observed between overall complications became more pronounced with increasing age category, with men always having higher complication rates than women ( $\leq 50: 1.43 \%$, age $50-59: 2.06 \%$, age $60-69$ : $1.08 \%$, age $70-79: 4.63 \%$, age $\geq 80: 5.54 \% ; p<0.0001)$. On the other hand, the increase in the complication rate with higher comorbidity was not significantly different between men and women (Fig. 1a).

The unadjusted in-hospital mortality rate was almost double $(1.46 \%$ vs. $0.84 \%)$ in men compared with women $(p<0.0001)$. Using a multivariable logistic regression analysis for in-hospital mortality, adjusting for potential confounders, we found that women had a reduced risk of in-hospital death (OR 0.64, 95\% Cl 0.49-0.83) (Table 3).
Women were less likely to experience in-hospital mortality after kidney surgery when compared to men for all age groups $(p<0.0001)$ (Fig. 1b). Similarly, female gender had a lower in-hospital mortality for each Charlson score category $(p=0.0012)$. When mortality was examined by gender and stratified by treatment type, we found that women had a lower in-hospital mortality compared to men for both RN and $\mathrm{PN}(0.97 \%$ vs. $1.62 \% ; 0.23 \%$ vs. $0.67 \%$, respectively, $p<0.0001$ ) (Fig. 1b).

\section{Discussion}

New healthcare programs and government mandated quality initiatives aim to decrease treatment-related disparities. Institutions are attempting to monitor patient's access to care and treatment decision-making. Yet, studies examining renal 
Minnillo et al.

\begin{tabular}{|c|c|c|c|c|}
\hline \multirow{2}{*}{ Variable } & \multicolumn{2}{|c|}{ Radical nephrectomy } & \multicolumn{2}{|c|}{ Partial nephrectomy } \\
\hline & OR (95\% Cl) & $p$ value & OR $(95 \% \mathrm{Cl})$ & $p$ value \\
\hline $\begin{array}{l}\text { Age } \\
\text { category }\end{array}$ & & $<0.0001$ & & $<0.0001$ \\
\hline$<50$ & Referent & & Referent & \\
\hline $50-59$ & $0.98(0.88-1.08)$ & & $1.11(0.92-1.35)$ & \\
\hline $60-59$ & $1.14(1.03-1.25)$ & & $1.27(1.05-1.53)$ & \\
\hline $70-79$ & $1.39(1.26-1.53)$ & & $1.62(1.32-1.98)$ & \\
\hline$\geq 80$ & $1.74(1.52-1.98)$ & & $2.36(1.59-3.50)$ & \\
\hline $\begin{array}{l}\text { Charlson } \\
\text { category }\end{array}$ & & $<0.0001$ & & $<0.0001$ \\
\hline 0 & Referent & & Referent & \\
\hline 1 & $1.88(1.73-2.05)$ & & $1.66(1.38-1.99)$ & \\
\hline 2 & $3.57(3.19-4.00)$ & & $2.45-1.86-3.24)$ & \\
\hline$\geq 3$ & $6.22(5.18-7.48)$ & & $5.68(3.72-8.66)$ & \\
\hline $\begin{array}{l}\text { Gender } \\
\text { (F vs. M) }\end{array}$ & $0.92(0.87-0.98)$ & 0.011 & $0.99(0.87-1.14)$ & 0.93 \\
\hline
\end{tabular}

surgery stratified by gender are not frequently reported in the urologic literature. While reports have had varied results on gender equality in the type of surgery performed, our study showed that men and women were equally likely to undergo $\mathrm{RN}$ or PN. Also, we found that men had an absolute difference of $2.4 \%$ more complications than woman. Women had a lower overall complication rate even after adjusting for potential confounders as noted above (i.e., gender, year of surgery, patient age, geographical region).

Our analysis revealed that in-hospital mortality for both $\mathrm{RN}$ and $\mathrm{PN}$ was lower for women. A recent publication using Nationwide Inpatient Sample data (1998-2007) reported that women were less likely to experience postoperative complications and in-hospital mortality. ${ }^{12}$ After stratification by surgical technique, Sammon and colleagues found that female gender was associated with a lower incidence of complications from open RN, open and laparoscopic PN, but not for laparoscopic RN. ${ }^{12}$

When we analyzed gender effect by age, complications were higher in men compared to women for all age

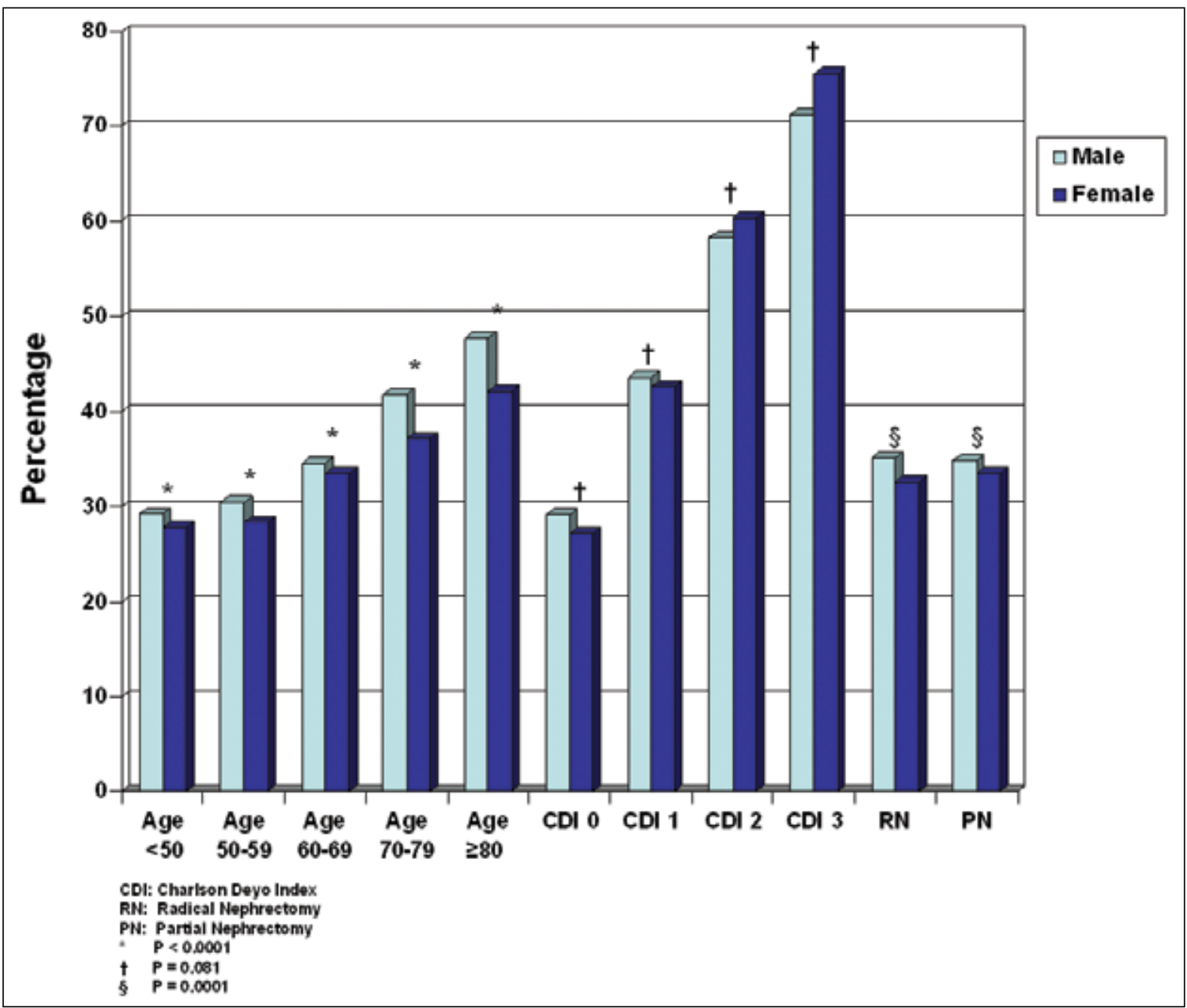

Fig. 1a. The effect of explanatory variables on all-complications stratified by gender. 
categories and the observed gender difference was more pronounced in older age groups (Fig. 1a). A recent multicentre international study showed an age/gender benefit for younger woman $\left(<59\right.$ years). ${ }^{13}$ Rampersaud and colleagues consider this is related to hormonal changes, ${ }^{13}$ although it is likely multifactorial. Multiple reports have demonstrated increasing age to be associated with a higher complication rate, including in-hospital mortality, after other genitourinary surgeries (i.e., radical prostatectomy).$^{14}$ Interestingly, the multicentre international study with 5654 patients found that age was an independent prognostic factor of diseasespecific survival for women, but not for men. The risk of RCC-specific death increases by about $1 \%$ with each year increase in age. ${ }^{13}$ In addition to increased postoperative complications, we observed that men were at a greater risk of in-hospital mortality for each age category (Fig. 1b).

Our study failed to demonstrate a gender disparity in the use of PN to treat renal masses, which is in contrast to other studies. Dulabon and colleagues showed that men have a 1.22 times greater odds of being treated with PN compared to women. ${ }^{15}$
This is despite data from the Surveillance, Epidemiology and End-Results (SEER) program suggesting that men present with larger, higher grade and higher stage tumours than women, which may require some men to receive $\mathrm{RN} .{ }^{16}$ Utilizing PN helps prevent potential chronic kidney disease (CKD), which is important given the increasing diagnoses of small renal tumours. ${ }^{17,18}$ Advanced age has already been demonstrated as an independent risk factor for CKD; to help prevent future renal deterioration, there is increasing emphasis on using kidney preservation surgery for appropriate renal masses. ${ }^{3,15}$ If a gender disparity exists in the use of PN in the United States, the reasons for this need to be studied further.

Validation studies assessing the use of ICD-9 and ICD-10 diagnosis codes from administrative data in the identification of comorbidity and complications have demonstrated good agreement with patient medical records. ${ }^{11}$ A number of studies have examined the $\mathrm{CIHI}$ diagnostic and procedural data using chart review as the gold standard and found high agreement for primary diagnosis (81\%-95\%) and secondary diagnosis (88\%-99\%). ${ }^{9,10}$ In-hospital mortality was over $99 \%$ accurate.

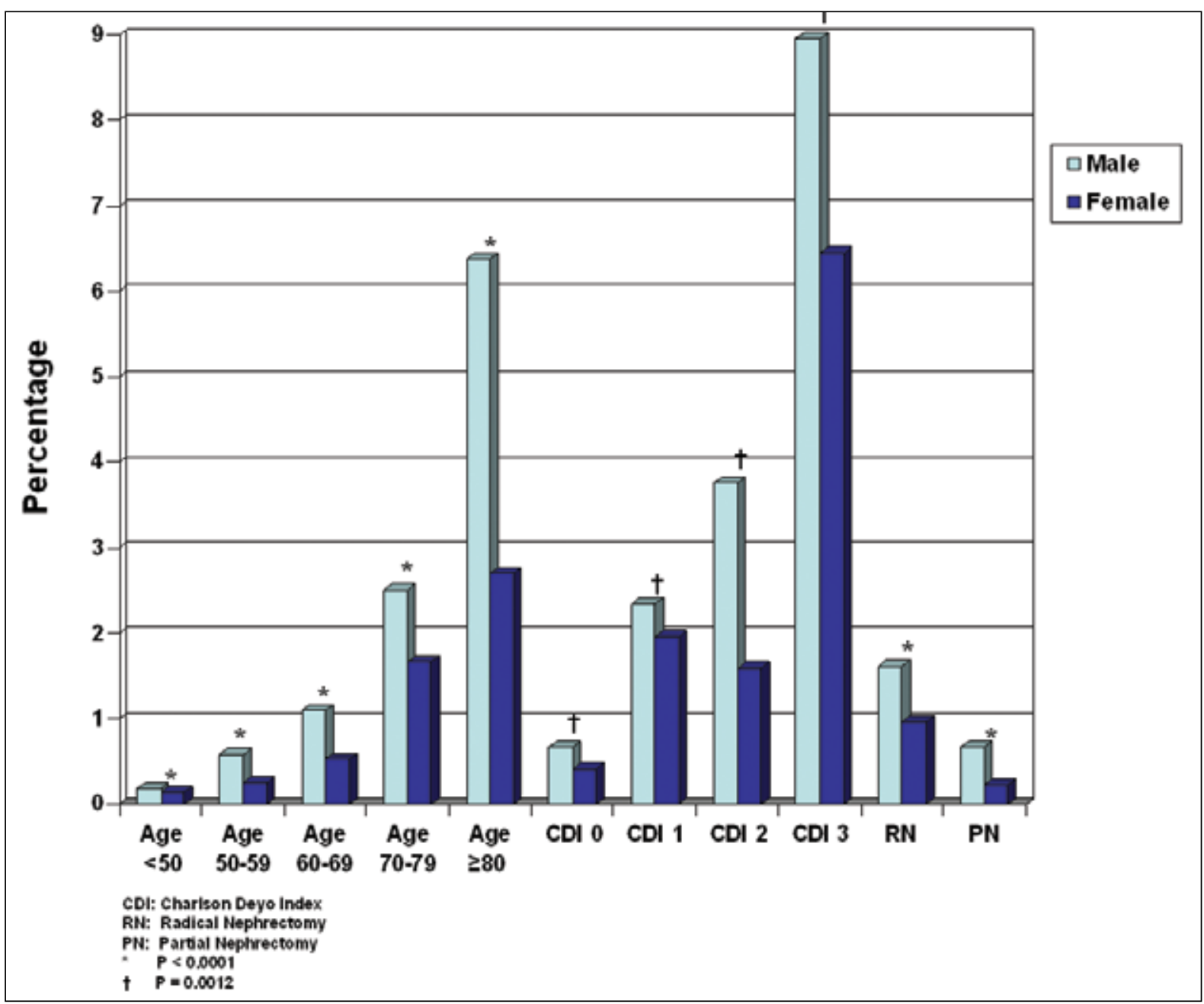

Fig. $\mathbf{1 b}$. The effect of explanatory variables on in-hospital mortality stratified by gender. 


\begin{tabular}{|c|c|c|c|}
\hline Variable & OR & $95 \% \mathrm{Cl}$ & $p$ value \\
\hline Gender (F vs. M) & 0.64 & $0.49-0.83$ & 0.0009 \\
\hline Age $<50$ & Referent & Referent & \\
\hline $50-59$ & 2.39 & $1.08-5.29$ & $<0.0001$ \\
\hline $60-69$ & 4.00 & $1.90-8.41$ & $<0.0001$ \\
\hline $70-79$ & 8.59 & 4.14-17.7 & $<0.0001$ \\
\hline$\geq 80$ & 18.1 & 8.61-37.9 & $<0.0001$ \\
\hline \multicolumn{4}{|l|}{ Charlson category } \\
\hline 0 & Referent & Referent & \\
\hline 1 & 4.50 & $3.32-6.10$ & $<0.0001$ \\
\hline 2 & 4.88 & $3.51-6.77$ & $<0.0001$ \\
\hline$\geq 3$ & 13.9 & $9.45-20.4$ & $<0.0001$ \\
\hline Procedure (PN vs. RN) & 0.45 & $0.29-0.71$ & 0.0006 \\
\hline
\end{tabular}

OR: odds ratio; $\mathrm{Cl}$ : confidence interval; $\mathrm{F}$ : female; $\mathrm{M}$ : male; $\mathrm{PN}$ : partial nephrectomy; RN: radical nephrectomy.

One of the main limitations of our study is its retrospective nature, which makes the data susceptible to the effects of unmeasured confounders. Factors that could have affected the postoperative complications, such as a patient's body mass index, tumour size, stage, hospital setting and performance status, were not recorded in this database. It is well-known that tumour size and stage, which we could not account for, are important factors in the treatment selection for RCC. A multi-institutional, international study by Chen and colleagues demonstrated that female patients had lower grade renal tumours when compared to male. ${ }^{19}$ However, they did not observe a statistically significance difference in mean tumour size between men and women. Also, we did not have length of stay, readmission rate, and Clavien grade for the complications, which would have provided a more comprehensive assessment of perioperative morbidity.

Estimates of comorbidities and complications using administrative datasets can be criticized since they can be undercoded. Re-abstraction studies demonstrate sensitivity of $53 \%$ to $99 \%$ for major medical conditions, ${ }^{9}$ thus some comorbidity information is invariably lost. However, given that the degree of undercoding is unlikely to differ between men and women, this should not explain the gender difference in the observed complications of kidney surgery. In addition, the capture of in-hospital mortality is nearly $100 \%$. Thus, we feel that our study provides a good estimate of the gender effect on in-hospital morbidity and mortality.

\section{Conclusions}

Our population-based analysis, which includes data from both community and tertiary-care hospitals, demonstrated a lower complication and in-hospital mortality rate after renal surgery for women compared to men. The difference in complication rates appears to be restricted to patients undergoing $\mathrm{RN}$ and is more pronounced in the elderly. Further study is needed to determine if the observed effect is related to differ- ences in surgical difficulty or if it is related to confounders, such as tumour size and tumour stage.

Competing interests: Dr. Minnillo, Dr. Horowitz, Dr. Ponsky and Dr. Abouassaly all declare no competing financial or personal interests. Dr. Finelli has also participated in clinical trials in the past 2 years for Amgen, Astellas, Janssen and Ferring. Dr. Alibhai has received a grant from Sanofi to study the treatment of ADT-related fatigue.

This paper has been peer-reviewed.

\section{References}

1. Robson CJ, Churchill BM, Anderson W. The results of radical nephrectomy for renal cell carcinoma. J Urol 1969;101:297-301.

2. Campbell SC, Novick AC, Bukowski RM. Renal Tumors. In Wein AJ Kavoussi LR, Novick AC, Partin AW, Peters CA eds. Campbell's Urology, 9th ed. Vol 2. Philadelphia: WB Saunders, 2007;1608-16.

3. Uzzo RG, Novack AC. Nephron sparing surgery for renal tumors: Indications, techniques and outcomes. J Urol 2001;166:6-18. http://dx.doi.org/10.1016/S0022-5347(05)66066-1

4. Woldrich JM, Mallin K, Ritchey J, et al. Sex differences in renal cell cancer presentation and survival: An analysis of the National Cancer Database, 1993-2004. J Urol 2008;179:1709-13. http://dx.doi. org/10.1016/i.juro.2008.01.024

5. Hew MN, Zonneveld R, Kümmerlin IP, et al. Age and gender related differences in renal cell carcinoma in a European cohort. J Urol 2012;188:33-8. http://dx.doi.org/10.1016/i.juro.2012.02.2573

6. Campbell SC, Novick AC, Streem SB, et al: Complications of nephron sparing surgery for renal tumors. J Urol 1994;151:1177-80

7. Thompson RH, Leibovich $B C$, Lohse $C M$, et al. Complications of contemporary open nephron sparing surgery: A single institution experience. J Urol 2005;174:855-8. http://dx.doi.org/10.1097/01. ju.0000169453.29706.42

8. Abouassaly R, Alibhai SMH, Tomlinson GA, et al. The effect of aging on the morbidity of kidney surgery. J Urol 2011;186:811-6. http://dx.doi.org/10.1016/i.juro.2011.04.077

9. Canadian Institute for Health Information, CIHI Data Quality Study of the 2006-2007 Discharge Abstract Database. Ottawa, Ont; 2009.

10. Hawker GA, Coyte PC, Wright JG, et al. Accuracy of administrative data for assessing outcomes after knee replacement surgery. J Clin Epidemiol 1997;50:265-73. http://dx.doi.org/10.1016/S08954356(96)00368-X

11. Lawthers AG, MCCarthy EP, Davis RB, et al. Identification of in-hospital complications from claims data. Is it valid? Med Care 2000;38:785-95. http://dx.doi.org/10.1097/00005650-200008000-00003

12. Sammon J, Trinh $Q-D$, Sun $M$, et al. The effect of gender on nephrectomy perioperative outcomes: $A$ national survey. Can J Urol 2012;19:6337-44.

13. Rampersaud EN, Klatte T, Bass $G$, et al. The effect of gender and age on kidney cancer survival: Younger age is an independent prognostic factor in women with renal cell carcinoma. Urol Oncol 2014;32:30. e9-13. http://dx.doi.org/10.1016/i.urolonc.2012.10.012. Epub 2013 Feb 17.

14. Alibhai SMH, Leach M, Tomlinson G, et al. 30-day mortality and major Complications after radical prostatectomy: Influence of age and comorbidity. J Natl Cancer Inst 2005;97:1525-32. http://dx.doi. org/10.1093/inci/dij313

15. Dulabon $L M$, Lowrance WT, Russo $P$, et al. Trends in renal tumor surgery delivery in the United States. Cancer 2010;116:2316-21.

16. Aron $M$, Nguyen $M M$, Stein RJ, et al. Impact of gender in renal cell carcinoma: An analysis of the SEER database. Eur Urol 2008;54:133-40. http://dx.doi.org/10.1016/.eururo.2007.12.001

17. Patard JJ. Incidental renal tumors. Curr Opin Urol 2009;19:454-8. http://dx.doi.org/10.1097/ MOU.0b013e32832f0ccd

18. Jewett MA, Zuniga A. Renal tumor natural history: The rationale and role for active surveillance. Urol Clin North Am 2008;35:627-34. http://dx.doi.org/10.1016/i.ucl.2008.07.004

19. Chen J, Shi B, Zhang D, et al. The clinical characteristics of renal cell carcinoma in female patients. Int J Urol 2009;16:554-7. http://dx.doi.org/10.1111/i.1442-2042.2009.02309.x

Correspondence: Dr. Robert Abouassaly, Urology Institute and Case Comprehensive Cancer Center, University Hospitals Case Medical Center, Seidman Cancer Center, 11100 Euclid Ave., Cleveland, OH 44106; robert.abouassaly@uhhospitals.org 